\title{
PULMONARY ARTERIAL CIRCULATION TIME, PULMONARY ARTERIAL BLOOD VOLUME, AND THE RATIO OF GAS TO TISSUE VOLUME IN THE LUNGS OF DOGS *
}

\author{
By KHALIL A. FEISAL, JORGE SONI † AND ARTHUR B. DuBOIS $\ddagger$
}

\author{
(From the Department of Physiology of the Graduate School of Medicine, University of \\ Pennsylvania, Philadelphia, Pa.)
}

(Submitted for publication July 7, 1961 ; accepted October 5, 1961)

The concept of a fixed relation between the pulmonary circulation time, the volume of blood in the lungs, and the cardiac output was introduced by Stewart (1) and developed and extended by Hamilton, Moore, Kinsman and Spurling (2). A rigorous mathematical analysis of the validity of calculations based on this relation has been presented more recently by Meier and Zierler (3). The introduction of techniques for left atrial catheterization has permitted Dock and co-workers (4) and others (5) to use indicator dilution techniques to measure the pulmonary blood volume in man. Although the volume of blood in the gas exchange vessels (i.e., "pulmonary capillaries") can be measured during life (6), the further subdivision of blood in the lung between the conducting arteries and the veins has not hitherto been feasible. Since such information would be of interest in health as well as in various abnormal circulatory states, we have developed a method for determining the volume of blood in the nonexchanging part of the pulmonary arterial tree.

This method is based on the same principle as that for determining the volume of a vascular compartment from flow and time data, and is dependent upon the availability of an indicator which can be injected into the pulmonary artery and which can be detected as soon as it arrives at the

* The support of a contract, DA-18-108-CML-6556, with the Chemical Corps Medical Laboratories, Army Chemical Center, is gratefully acknowledged. This work was supported in part by a training grant, HTS-5430 (C1), from the National Heart Institute, National Institutes of Health, United States Public Health Service.

† International Postdoctoral Research Fellow of the National Institutes of Health. Present address: Institute of Cardiology, Mexico City, Mexico.

$\ddagger$ This work was done during the tenure of an Established Investigatorship of the American Heart Association. site of gas exchange. The circulation time thus obtained, when multiplied by the pulmonary blood flow, yields the volume of the conducting (nonexchanging) portion of the pulmonary arterial tree.

We have used ether, injected as a solution into the main pulmonary artery, as the indicator for measuring the desired circulation time. As soon as it arrives in the pulmonary capillaries and because of its absence normally from the alveolar gas, it vaporizes and enters the alveoli, and continues to do so until its partial pressure in the alveolar gas equals its partial pressure in the pulmonary capillary blood. Ether is carried in the blood solely in physical solution. By calculations similar to those published by Forster (7), the alveolar tension of ether will equal 99 per cent of its tension in blood in 0.01 to 0.02 second. Assuming a mean capillary traversal time of 0.2 second in the dog [this figure is based on that calculated by Roughton (8) for man, assuming a rough correlation between capillary traversal time and body size] means that equilibrium is reached within the first 0.1 to 0.05 of the capillary length or sooner. Thus the volume measured by the method to be described should include a negligible fraction of the capillary blood.

Detection of ether in the breath, as used normally in the arm-to-lung circulation time method, involves too long a delay, owing to the flow of air through the tracheobronchial tree, to allow accurate determination of the time of arrival of ether in the capillaries. If, however, the animal is enclosed within a body plethysmograph, the arrival of ether at the site of gas exchange can be detected almost instantaneously as a rise in plethysmograph pressure caused by the entry of gaseous ether into the alveoli. Thus it becomes possible to define accurately the circulation time from the 
injection site in the pulmonary artery to the point at which gas exchange begins, and the pulmonary arterial volume can be calculated as mentioned above.

One objection to ether is that it boils at $34.5^{\circ}$ $\mathrm{C}$, and thus might be expected to form bubbles in the blood stream before arriving in the capillaries, leading to an erroneously short circulation time. This difficulty was encountered in our early experiments: injections of pure ether into various heart chambers and into the superior vena cava gave the same value of 0.2 second for circulation time, indicating that bubbles had formed in the blood stream. The problem was solved by dissolving ether in alcohol or in an emulsion composed principally of cottonseed oil, ${ }^{1}$ thus raising its boiling point. In order to evaluate the effect of this maneuver, the rate of bubble formation after injection of various concentrations of ether in alcohol was observed. For this purpose a large bottle was filled with tap water maintained at $38^{\circ}$ to $40^{\circ} \mathrm{C}$, and an opening near the bottom of the bottle was connected to a short piece of rubber tubing, which in turn was connected to a long glass tube. The rate of flow out of the bottle was adjusted to approximate the pulmonary blood flow in the dog by means of a screw clamp on the rubber tubing. Injections were made through a cardiac catheter inserted into the bottle and with the tip lying in the glass portion of the tube. Injection of ether alone led to the formation of bubbles at the tip of the catheter. In contrast, when a $1: 3$ or $1: 4$ solution of ether in alcohol was injected, no bubbles were seen over a distance of at least $40 \mathrm{~cm}$ from the tip of the catheter. Our experience with the lipid emulsion as a vehicle for ether has been similar to that when alcohol was used for this purpose, and both vehicles have been found to be satisfactory in experiments.

\section{PROCEDURE}

Dogs weighing 12 to $22 \mathrm{~kg}$ were anesthetized with sodium pentobarbital (25 $\mathrm{mg}$ per $\mathrm{kg}$ ). A shortened no. 9 cardiac catheter (volume $0.9 \mathrm{ml}$ ) was introduced through an external jugular vein into the pulmonary artery. The dog was then enclosed in a horizontal Plexiglas body plethysmograph, ${ }^{2}$ paralyzed with succinylcholine, and ventilated with a Starling pump. The pulmonary artery pres-

1 Lipomul; The Upjohn Co., Kalamazoo, Mich.

2 Made for us by Air-Shields, Inc., Hatboro, Pa. sure and the plethysmograph pressure were measured by means of Lilly capacitance manometers connected to a 4-channel direct-writing recorder. ${ }^{3}$ The electrocardiogram was monitored continuously on a cathode ray oscilloscope.

The plethysmograph consists of a Plexiglas baseplate, 54 inches long and 26 inches wide, and of a Plexiglas box, $48 \times 22 \times 22$ inches, completely removable, that can be held in place and made airtight by trunk clasps and a rubber gasket. Two portholes are provided to allow access to the animal without removing the top. The box is divided by a Plexiglas plate into two compartments of approximately equal volume when the animal is in the box; the lower compartment holds the animal, while the upper is connected to the opposite side of the differential monometer, thus serving as a compensating chamber to minimize baseline shifts caused by changing barometric pressure, ambient temperature, and random noise and vibration. The response of the whole system was 90 per cent complete in 0.05 second.

In earlier experiments we used a larger body plethysmograph (volume, $680 \mathrm{~L}$ ) and a differential strain gauge manometer. ${ }^{4}$ The larger plethysmograph is less sensitive and thus has a lesser signal-to-noise ratio.

The plethysmograph was calibrated by the injection and withdrawal of $10 \mathrm{ml}$ of air with a syringe. The sensitivity of the system was such that this volume change gave a deflection on the record of 20 to $30 \mathrm{~mm}$ with the animal in the lower chamber.

After calibration, $0.5 \mathrm{ml}$ of a $1: 4$ ether in alcohol or ether in Lipomul solution was instilled into the cardiac catheter. The respiratory pump was then stopped, its tubes clamped, and the ether flushed in rapidly with $3 \mathrm{ml}$ of saline. The time and duration of injection were recorded by means of a magnet attached to the plunger of the syringe and moving out of a coil. The volume of solution injected to flush in the ether appeared in the record of plethysmograph pressure as a displacement equivalent to $3 \mathrm{ml}$.

Dye dilution curves were obtained by injecting indocyanine green 5 into the pulmonary artery, with continuous sampling of blood from the femoral artery through a cuvet densitometer. ${ }^{6}$ Shortly ( 2 to 3 minutes) after the curve was inscribed, an injection of dye was made into the left atrium through a needle previously introduced by the transbronchial route (9) and another curve obtained. A number of curves was obtained, alternating the site of injection. Time-concentration curves were plotted on semilogarithmic graph paper and recirculation was detected and excluded from the calculation by projecting the linear portion of the downslope through two logarithmic cycles. Cardiac output was calculated as usual by the Stewart-Hamilton formula (2).

3 The Grass Instrument Co., Quincy, Mass.

4 Statham model PM $97 \mathrm{TC} \pm 0.05$ to $350 \pm 0.05$ PSID.

5 Cardiogreen; Hynson, Westcott and Dunning Inc., Baltimore, Md.

${ }^{6}$ Model X250A; The Waters Corporation, Rochester, Minn. 

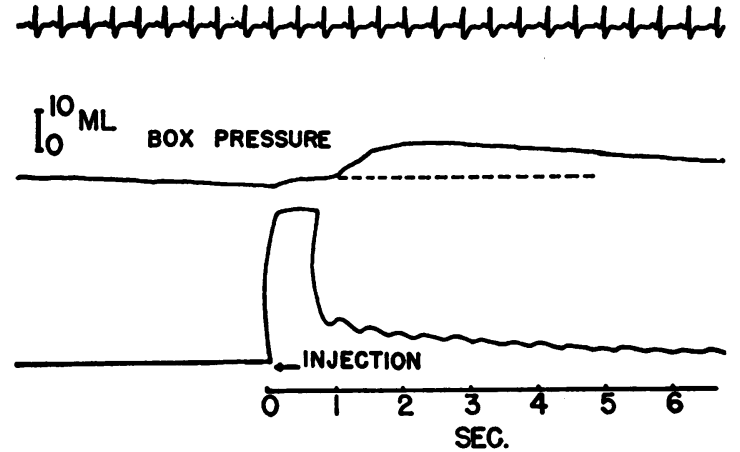

Fig. 1. RECORD OF INJECTION OF $1.0 \mathrm{ML}$ OF $1: 4$ ETHERALCOHOL MIXTURE WITH 2 ML SALINE INTO THE PULMONARY ARTERY OF A DOG. Top record: electrocardiogram. Center: box pressure, with calibration on the left. Bottom: record of injection through cardiac catheter, using pulmonary artery pressure gauge. Time base is in seconds.

The difference between the mean transit times from the pulmonary artery to the femoral artery and from the left atrium to the femoral artery gave the pulmonary mean transit time, and the difference between the dilution volumes gave the pulmonary blood volume.

\section{RESULTS}

Figure 1 shows the type of record obtained using ether in alcohol. The first rise in the tracing labeled "box pressure" is caused by the injection of saline to flush the solution of ether in alcohol from the catheter into the pulmonary artery. The subsequent rise in pressure reflects the entry of ether gas into the alveoli, until a peak is reached. As blood continues to enter the capillaries, the gradient is reversed and ether leaves the alveoli and passes back into the blood, producing a fall in box pressure, at a slow rate dependent on the solubility of ether in blood, the partial pressure gradient for ether, and the rate of pulmonary blood flow.

The volume of ether gas evolved in the alveoli was calculated as follows. A line was drawn through the plateau of the rise in plethysmograph pressure caused by the injection of $3 \mathrm{ml}$ of liquid and used as a baseline. In cases where the plateau was not distinct because of the superimposition of the early part of the rise caused by ether gas, an increment corresponding to a volume of $3 \mathrm{ml}$ (the volume injected) was measured from the initial baseline and a line drawn through it parallel to the initial baseline and used as a baseline, as above. The vertical distance between the corrected baseline and the top of the pressure tracing was then measured and multiplied by the calibration factor to give the volume of gas evolved. This was generally between 3 and $7 \mathrm{ml}$. Liquid ether, becoming gaseous, would expand as follows :

$$
\begin{aligned}
\frac{\text { vol ether gas }}{\text { vol liquid ether }}= & \frac{\text { density liquid ether }}{\text { mol wt ether }} \\
& \times \frac{273+T}{273} \times \frac{760}{713} \times 22,400
\end{aligned}
$$

Assuming a body temperature of $37^{\circ} \mathrm{C}$, a barometeric pressure of $760 \mathrm{~mm} \mathrm{Hg}$, density of ether of 0.71 at $20^{\circ} \mathrm{C}$, and molecular weight of ether of 74 , the volume of gas evolved per volume of liquid ether injected would be $260 \mathrm{ml}$ BTPS per $\mathrm{ml}$. Thus, $0.1 \mathrm{ml}$ of liquid ether could form as much as $26 \mathrm{ml}$ of gas. However, only a fraction of the ether injected forms gas, the rest remaining in solution in the capillary blood and tissues of the lungs. Volume of gas evolved $=$ (volume liquid ether injected $\times 260 \times$ alveolar volume)/ (partition coefficient of ether $\times$ capillary and tissue volume + alveolar volume). If the volume injected is $0.1 \mathrm{ml}$, the partition coefficient of ether between water and gas is 15.5 (10), and the ratio of alveolar volume to capillary plus tissue volume is approximately $3: 1$, then the volume of gas evolved is $4.2 \mathrm{ml}$ BTPS. Similarly, if the volume of gas evolved is measured and the volume injected is known, one may calculate the ratio of alveolar volume to capillary plus tissue volume, or the lung density, as follows:

$$
\begin{aligned}
& \frac{\text { alveolar vol }}{\text { cap. }+ \text { tissue vol }}=\frac{15.5 \times \text { vol gas evolved }}{260 \times \text { vol liquid ether inj. }- \text { vol gas evolved }} \text { or } \frac{15.5}{\frac{260 \times \text { vol liquid ether inj. }}{\text { vol gas evolved }}-1} \\
& \quad \text { or lung density }=\frac{1}{1+\frac{\text { alveolar vol }}{\text { cap. }+ \text { tissue vol }}}=\frac{1}{1+\frac{15.5 \times \text { vol gas evolved }}{260 \times \text { vol liquid ether inj, - vol gas evolved }}}
\end{aligned}
$$


Taking the mean volume, $4.8 \mathrm{ml}$ of gas evolved as a result of injecting $0.1 \mathrm{ml}$ of liquid ether, the ratio of alveolar volume to volume of capillary blood and tissues would be 3.5 or the lung density would be $1 /(1+3.5)=0.22 \mathrm{~g}$ per $\mathrm{ml}$.

This volume of ether ( $5 \mathrm{ml}$ BTPS) distributed in an alveolar gas volume of $1 \mathrm{~L}$ would yield an alveolar concentration of 0.5 per cent ether, a peak arterial blood concentration of $21 \mathrm{mg}$ per $100 \mathrm{ml}$, and would momentarily lower the arterial oxygen tension by about $0.5 \mathrm{~mm} \mathrm{Hg}$; thus, the systemic effects would be minimal. If all the blood were shunted past the lungs, the peak concentration of ether in the arterial blood would be greater, and an arterial ether curve similar to an arterial dye dilution curve would be expected. Thus, ether injection followed by arterial ether analysis could be used as a method for measuring right-to-left shunt. The arterial blood was not analyzed for oxygen or ether during this study.

In order to ascertain that the rise in plethysmograph pressure was not caused by bubbles forming in the blood stream, ether in alcohol was injected at different sites into the venous circulation. Figure 2 shows tracings of records of injection into the pulmonary artery, the right ventricle, and a peripheral vein, superimposed so that the injection points coincide in time. It can be seen that there is a proportionate increase in circulation time and a slight decrease in volume evolved as the site of injection moves away from the pulmonary capillaries.

Disturbances in the plethysmograph pressure record occur and can be caused by a number of factors. The commonest such regular phenomenon is the recurrent transient oscillation caused by the heart beat; its magnitude corresponds usually to less than $1 \mathrm{ml}$, but is never such as to render the record uninterpretable.

An increase in plethysmograph pressure is regularly produced upon closing the portholes by heating of the air surrounding the animal. Repeated venting of the plethysmograph minimizes this trend and the baseline drift is minimal after 1 to 2 minutes. Another source of drift is the Lilly manometer head which is sensitive to changes in ambient temperature. The difference in rate between $\mathrm{CO}_{2}$ output and $\mathrm{O}_{2}$ uptake ( $\mathrm{RQ}$ effect), and a temperature gradient between the two chambers are other sources. The sum of

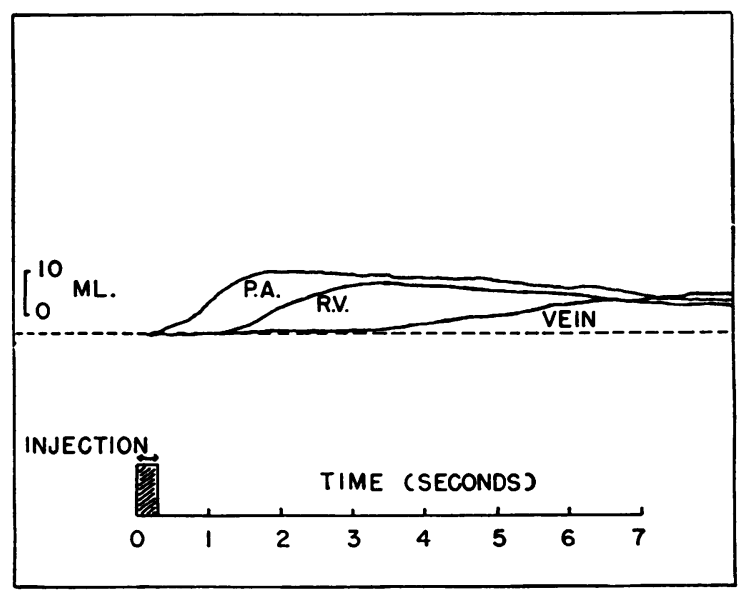

Fig. 2. INJECtion of ETHER IN ALCOHOL INTO DIFFERENT SITES IN THE CIRCULATORY SYSTEM OF THE DOG, SHOWING PROPORTIONATE INCREASE IN CIRCULATION TIME WITH INCREASING DISTANCE FROM THE PULMONARY CAPILLARIES.

these effects is variable, but is considered acceptable if it does not exceed $0.5 \mathrm{ml}$ per second. The presence of a compensating chamber stabilizes the record against changes in ambient temperature and barometric pressure, and decreases the effect of noise and vibration in the room. The plethysmograph is sensitive to jarring and noise, and in spite of careful handling and the presence of a compensating chamber, vibration artifacts still occur, but again they rarely render the record uninterpretable. Electrical noise caused by alternating current interference should be minimized by proper grounding of instruments because of the high sensitivity required. The minimal noise level is roughly equivalent to $0.2 \mathrm{ml}$; the noise level is considered acceptable until it becomes equivalent to a volume of $1 \mathrm{ml}$.

In analyzing the records, the circulation time in the pulmonary artery is measured between the time at which the rise of pressure caused by the injection artifact reaches half its maximum value, and the time at which the rise of plethysmograph pressure caused by the appearance of ether in the alveoli reaches half its peak value. The choice of the latter point is explained as follows. The volume of ether gas formed depends on the quantity of ether that has arrived at the site of gas exchange. There is a scatter of arrival times of ether at the site of gas exchange that is a consequence of different rates of flow to different parts 
TABLE I

A mount of gas evolved after injection of ether into pulmonary artery of dogs *

\begin{tabular}{|c|c|c|c|}
\hline Dog & $\begin{array}{l}\text { Amount of } \\
\text { ether in- } \\
\text { jected } \dagger\end{array}$ & $\begin{array}{l}\text { Volume of gas } \\
\text { evolved }\end{array}$ & $\begin{array}{l}\text { Pulmonary } \\
\text { arterial } \\
\text { circulation } \\
\text { time }\end{array}$ \\
\hline & $m l$ & $m l$ & $\mathrm{sec}$ \\
\hline 1 & $\begin{array}{l}0.2 \\
0.2\end{array}$ & $\begin{array}{r}9.3 \\
11.7\end{array}$ & $\begin{array}{l}1.72 \\
2.08\end{array}$ \\
\hline 2 & $\begin{array}{l}0.1 \\
0.1\end{array}$ & $\begin{array}{l}5.0 \\
6.2\end{array}$ & $\begin{array}{l}1.26 \\
1.88\end{array}$ \\
\hline 3 & $\begin{array}{l}0.1 \\
0.1 \\
0.1 \\
0.1\end{array}$ & $\begin{array}{l}4.2 \\
6.0 \\
7.3 \\
6.4\end{array}$ & $\begin{array}{l}1.12 \\
1.20 \\
1.32 \\
0.88\end{array}$ \\
\hline 4 & $\begin{array}{l}0.2 \\
0.2 \\
0.2 \\
0.2\end{array}$ & $\begin{array}{l}8.9 \\
8.6 \\
8.4 \\
6.7\end{array}$ & $\begin{array}{l}0.40 \\
0.65 \\
0.68 \\
0.67\end{array}$ \\
\hline 5 & $\begin{array}{l}0.2 \\
0.2 \\
0.2 \\
0.2\end{array}$ & $\begin{array}{l}8.0 \\
6.0 \\
6.5 \\
6.2\end{array}$ & $\begin{array}{l}0.87 \\
0.66 \\
1.11 \\
1.00\end{array}$ \\
\hline 6 & $\begin{array}{l}0.1 \\
0.1 \\
0.1 \\
0.1 \\
0.1\end{array}$ & $\begin{array}{l}5.3 \\
4.4 \\
3.9 \\
3.7 \\
7.0\end{array}$ & $\begin{array}{l}1.44 \\
1.77 \\
1.72 \\
1.56 \\
1.12\end{array}$ \\
\hline 7 & $\begin{array}{l}0.1 \\
0.1 \\
0.1 \\
0.2\end{array}$ & $\begin{array}{l}5.0 \\
6.0 \\
3.5 \\
8.5\end{array}$ & $\begin{array}{l}0.64 \\
0.72 \\
0.92 \\
0.80\end{array}$ \\
\hline 8 & $\begin{array}{l}0.1 \\
0.1 \\
0.1 \\
0.1 \\
0.1 \\
0.1\end{array}$ & $\begin{array}{l}2.9 \\
3.1 \\
2.3 \\
1.5 \\
1.8 \\
3.6\end{array}$ & $\begin{array}{l}0.76 \\
1.02 \\
1.32 \\
1.32 \\
1.04 \\
1.04\end{array}$ \\
\hline 9 & $\begin{array}{l}0.1 \\
0.1\end{array}$ & $\begin{array}{l}6.0 \\
5.1\end{array}$ & $\begin{array}{l}1.16 \\
1.17\end{array}$ \\
\hline 10 & $\begin{array}{l}0.12 \\
0.12 \\
0.14 \\
0.16\end{array}$ & $\begin{array}{r}6.3 \\
8.1 \\
7.7 \\
11.4\end{array}$ & $\begin{array}{l}0.55 \\
0.68 \\
0.64 \\
0.60\end{array}$ \\
\hline 11 & $\begin{array}{l}0.1 \\
0.1 \\
0.1\end{array}$ & $\begin{array}{l}5.4 \\
6.0 \\
4.2\end{array}$ & $\begin{array}{l}1.4 \\
1.4 \\
1.6\end{array}$ \\
\hline 12 & $\begin{array}{l}0.1 \\
0.1 \\
0.1 \\
0.1 \\
0.1 \\
0.1\end{array}$ & $\begin{array}{l}3.0 \\
4.3 \\
3.0 \\
3.3 \\
3.0 \\
3.6\end{array}$ & $\begin{array}{l}0.68 \\
0.72 \\
0.72 \\
0.88 \\
0.60 \\
0.88\end{array}$ \\
\hline
\end{tabular}

* Time between midinjection and midrise of plethysmograph pressure.

t The vehicle used as a solvent for ether was ethyl alcohol, except during the third and fourth injections of Dog 7, in which Lipomul was used. The volume of solvent used was 4 times the volume of ether injected. of the lung. The midvolume point of the rise in plethysmograph pressure corresponds to the time of arrival of half the ether in the lung. If ether is mixed uniformly with the blood, the concentration of ether in all branches of the pulmonary artery will be equal, and the arrival of half the ether would indicate the arrival of half the blood at the site of gas exchange. ${ }^{7}$

Table I gives the values for the circulation time and volume evolved as a result of injecting the solution of ether in alcohol into the pulmonary artery in 12 dogs. The variability in these measurements of time is discussed later. Table II gives the cardiac outputs and the pulmonary artery circulation times in 5 dogs, as well as values computed from these for pulmonary artery volume and total pulmonary circulation time. The ratio of pulmonary artery circulation time to total pulmonary circulation time averaged 0.28 (range, 0.15 to 0.41 ) and the ratio of pulmonary artery volume to total pulmonary blood volume averaged 0.29 (range, 0.15 to 0.47 ). It must be noted that in spite of the near identity of the averaged ratios, the two ratios are different in every dog, owing to

7 If an accuracy greater than 5 per cent is required, it may be necessary to introduce two corrections in analyzing these curves. The first correction is the use of the "mean transit time" rather than the time required to reach 50 per cent of maximum rise, or "median transit time." This requires that the ether curve, assumed to be a cumulative frequency function, be treated in the same manner as a constant infusion of an indicator substance (3), viz, the area above the curve from zero to peak pressure is divided by the peak pressure to obtain the mean transit time. The mean transit time may also be obtained by differentiating the curve, thus giving it the configuration of an indicator dilution curve obtained after a single injection of indicator, then multiplying the change of pressure at a number of points in the curve by the respective time, and dividing the sum of these products by the total pressure change. Values obtained on several curves by the latter method were within 0.01 second of the median transit time. This difference was not enough to justify the routine use of the longer method of calculation. The pressure-time curve after injection of ether is probably not, strictly speaking, a cumulative frequency function, since some ether may return to the blood before peak pressure is reached. Consequently a correction for pressure decay at every point on the curve may be introduced. The correction would be proportional to the elapsed time, the degree of pressure change, and the rate constant of the descending curve. This correction was not applied to our curves because the rate of decay is small compared with the rate of rise. 
TABLE II

Values for pulmonary circulation in dogs *

\begin{tabular}{|c|c|c|c|c|c|c|}
\hline Dog & Wt & $\begin{array}{l}\text { Cardiac } \\
\text { output }\end{array}$ & $\begin{array}{l}\text { Circulation } \\
\text { time of } \\
\text { pulmonary } \\
\text { artery } \\
\text { PA-Cap }\end{array}$ & $\begin{array}{l}\text { Volume of } \\
\text { pulmonary } \\
\text { artery } \\
\text { PA-Cap }\end{array}$ & $\begin{array}{c}\text { Pulmonary } \\
\text { circulation } \\
\text { time } \\
\text { PA-LA }\end{array}$ & $\begin{array}{c}\text { Pulmonary } \\
\text { blood } \\
\text { volume } \\
\text { PA-LA }\end{array}$ \\
\hline & $\mathrm{kg}$ & $\mathrm{ml} / \mathrm{min}$ & sec & $m l$ & $\mathrm{sec}$ & $m l$ \\
\hline 3 & 13.5 & 1,902 & 1.1 & 35 & 4.6 & 102 \\
\hline 7 & 15.5 & 2,774 & 0.9 & 42 & 6.2 & 212 \\
\hline 9 & 21.0 & 2,932 & 0.7 & 39 & 2.8 & 262 \\
\hline 10 & 22.5 & 2,844 & 1.2 & 57 & 2.9 & 164 \\
\hline 11 & 20.0 & 3,307 & 1.5 & 83 & 4.2 & 210 \\
\hline
\end{tabular}

${ }^{*} \mathrm{PA}=$ pulmonary artery $; \mathrm{Cap}=$ capillaries $; \mathrm{LA}=$ left atrium.

the method of calculation. The ratio of circulation times involves using an average figure for cardiac output, whereas the ratio of the volumes involves dividing the cardiac output and blood volume measurement into two sets, one with left atrial injection and the other with pulmonary arterial injection of dye, and taking the difference between the averages of these two sets as the pulmonary blood volume. Thus the difference between the ratios is, in a sense, a reflection of the variability in the measurement of cardiac output. No previous measurement of these ratios is available for comparison on living animals. In isolated dog lung lobes and using a method based on the infusion of fluids of different viscosities, Piiper found the volume of blood proximal to the site of major vascular resistance to be 47 per cent of the total pulmonary vascular volume (11).

Table III gives the mean values of pulmonary arterial circulation time, volume of gas evolved for each $0.1 \mathrm{ml}$ of ether injected, and the ratio of alveolar gas volume to capillary plus tissue volume, calculated from the volume of gas evolved for each $0.1 \mathrm{ml}$ ether injected. The ratio of alveolar gas volume to capillary plus tissue volume averaged 3.6 (range, 1.7 to 4.8 ). This ratio would decrease with atelectasis, consolidation, pulmonary edema, or pulmonary vascular shunt. In some dogs full inflation was necessary to restore the aeration of the lungs. Thus, variations in this ratio may reflect changes in the aeration of the lungs during the course of anesthesia. The lung density was calculated by adding unity to the ratio of alveolar gas volume to capillary plus tissue volume, and taking the reciprocal of the sum. The average lung density was $0.23 \mathrm{~g}$ per $\mathrm{ml}$ (range,
0.17 to 0.36 ). The density would increase to unity if there were complete consolidation, atelectasis, edema, or pulmonary vascular shunt. It would decrease to zero if the lungs contained all air and no blood or tissue. A mean density of 0.23 is in keeping with the specific gravity of aerated lungs.

\section{DISCUSSION}

In general, values for the pulmonary artery circulation time obtained in rapid succession in an animal are very similar. However, over a long experimental period, a certain degree of variability is frequently observed. This variability may be caused by: 1) physiologic differences, 2) random errors, and 3) uncertainties in the measurement.

TABLE III

Mean values for pulmonary arterial circulation time, volume of gas per $0.1 \mathrm{ml}$ ether, the ratio of alveolar gas space to capillary and tissues space, and lung density in anesthetized dogs

\begin{tabular}{|c|c|c|c|c|}
\hline Dog & $\begin{array}{l}\text { Pulm. art. } \\
\text { circulation } \\
\text { time } \\
\text { PA-Cap }\end{array}$ & $\begin{array}{c}\text { Volume } \\
\text { ether } \\
\text { gas per } \\
\text { 0.1 ml } \\
\text { ether }\end{array}$ & $\frac{\text { Alv. gas vol }}{\text { Cap. +tissue vol }}$ & $\underset{\text { density }}{\text { Lung }}$ \\
\hline & $\sec$ & $m l$ & $\mathrm{ml} / \mathrm{ml}$ & $\mathrm{g} / \mathrm{ml}$ \\
\hline $\begin{array}{r}1 \\
2 \\
3 \\
4 \\
5 \\
6 \\
7 \\
8 \\
9 \\
10 \\
11 \\
12\end{array}$ & $\begin{array}{l}1.9 \\
1.6 \\
1.1 \\
0.6 \\
0.9 \\
1.5 \\
0.8 \\
1.1 \\
1.2 \\
0.6 \\
1.5 \\
0.7\end{array}$ & $\begin{array}{l}5.8 \\
5.6 \\
6.2 \\
4.1 \\
3.3 \\
4.8 \\
4.8 \\
2.5 \\
5.6 \\
6.0 \\
5.0 \\
3.7\end{array}$ & $\begin{array}{l}4.5 \\
4.3 \\
4.8 \\
2.9 \\
2.3 \\
3.5 \\
3.5 \\
1.7 \\
4.3 \\
4.7 \\
3.7 \\
2.6\end{array}$ & $\begin{array}{l}0.18 \\
0.19 \\
0.17 \\
0.26 \\
0.30 \\
0.22 \\
0.22 \\
0.36 \\
0.19 \\
0.18 \\
0.21 \\
0.28\end{array}$ \\
\hline $\begin{array}{l}\text { Mean } \\
\text { SD } \\
\text { SE }\end{array}$ & $\begin{array}{l}1.1 \\
0.4 \\
0.1\end{array}$ & $\begin{array}{l}4.8 \\
1.2 \\
0.3\end{array}$ & $\begin{array}{l}3.6 \\
1.0 \\
0.3\end{array}$ & $\begin{array}{l}0.23 \\
0.06 \\
0.02\end{array}$ \\
\hline
\end{tabular}




\section{Physiologic differences}

Differences may be observed among animals, and in the same animal studied on different occasions, and even during the same experimental session. Physiologic factors accounting for such differences include body size and changes in cardiac output and pulmonary blood volume with prolonged recumbency; the fact that the cardiac output and circulation times are not obtained simultaneously but may be separated by as much as an hour or more produces variability in the pulmonary artery volume measurement. Other factors are deterioration in the condition of the dog caused by prolonged anaesthesia with recumbency, hypoventilation, atelectasis, and cardiac failure.

In some dogs, usually toward the end of the experiment, the rise in plethysmograph pressure after injection of ether was markedly decreased. Some of these dogs died afterwards with gross pulmonary edema; in these instances the increase in the lung density owing to complete obstruction of alveoli by edema fluid may have contributed to the fact that a smaller volume of ether gas was evolved in the alveoli. The occurrence of atelectasis or the presence of anatomic shunt would give the same pattern. One dog, not included in this series, in which the rise caused by the injection of ether was unusually small, had a calculated pulmonary mean transit time from pulmonary artery to left atrium of 0.3 second, suggesting the presence of a right-to-left pulmonary arterial shunt. After death, a cast was made of the pulmonary arterial system, ${ }^{8}$ but no gross anatomic shunts could be detected.

Another source of random variability is the time of injection in relation to the cardiac cycle. The volume of blood in the pulmonary artery and the blood flow both vary with the cardiac cycle, and the volume obtained by this method is that existing at the moment when ether arrives at the site of gas exchange, since this is the volume which must be "swept out" before ether reaches this location. Similarly, blood flow theoretically should be integrated throughout the transit time.

Changes in the position of the catheter in the pulmonary artery may introduce variability in the pulmonary artery circulation time measure-

\footnotetext{
8 We are indebted to Dr. Oscar V. Batson for performing this procedure.
}

ment. Ideally one would like to check the catheter location immediately before each injection. This, however, involves taking off the top of the plethysmograph and checking it for leaks after the top is replaced; the disadvantages of this cumbersome maneuver may thus outweigh its advantages.

\section{Systematic and random recording errors}

Certain errors are introduced by the detectingrecording system. The volume of ether-alcohol mixture used does not fill the catheter, so that there is regularly a delay between the beginning of injection and the time when ether actually begins to enter the circulation. The exact time when the major part of the ether enters the circulation cannot be ascertained, but is probably close to or slightly before the middle of the injection period ( $3 \mathrm{ml}$ in 0.3 second). We have used the midpoint of the rise in the midtime of ether injection; the error thereby introduced probably does not exceed 0.05 second in either direction or roughly 5 per cent of the mean pulmonary artery circulation time.

Random errors in reading the midpoint of the rise due to the evolution of ether gas do not exceed 0.04 second, or roughly 3 per cent of the reading (range, 1 to 7 per cent). The paper speed of the recorder was timed with a stop watch and was accurate to within 2 per cent. The lag in the transmission of pressure from the site of gas absorption through the chest wall and to the pressure gauge is probably less than 0.02 second (12) or 2 per cent of the mean time. The maximum uncertainty owing to all the systematic and random recording errors thus is 0.13 second or about 10 per cent of the final value of the pulmonary arterial circulation time.

The random error in calculating pulmonary arterial blood volume depends on the sum of the variability in cardiac output measurements and in ether circulation times. The variability of cardiac output measurements by the dye dilution method is about \pm 10 per cent; that of ether circulation times, including physiologic variability and experimental error is about \pm 20 per cent. However, since the mean values for each of these circulation times were based on averaging approximately four separate determinations, the 
range of error would be halved. Therefore, the accuracy of the pulmonary arterial blood volumes listed in Table II is approximately \pm 15 per cent.

Uncertainties as to the nature of the volume measured

The question arises whether the volume measured by this method corresponds exactly to the volume of the pulmonary arterial tree. The catheter is placed in the main pulmonary artery just beyond the pulmonic valve. Inclusion of all the blood in the main pulmonary artery in the measurement would thus depend on the mixing of ether with the blood back to the pulmonic valve. Whether or not this occurred in our observations cannot be ascertained. When radiopaque dyes are injected into the main pulmonary artery, the pulmonic valve is occasionally outlined (13). The volume injected, the speed of injection, and the phase of the cardiac cycle during which the ether is injected, could all conceivably affect this mixing.

Non-uniform mixing of ether with the blood leaving the main pulmonary artery through its different branches would not invalidate the measurement, since the volume measured would continue to include the blood in all temporally equidistant channels, and since, in this special situation, all the cardiac output passes through the "detecting device," the lung, thus avoiding the sampling error in poor mixing.

At the end of the pulmonary arterial tree there is also some uncertainty as to the exact volume measured. Evidence has been recently presented by Staub that, under conditions of high oxygen tension, the diffusion of oxygen into the blood stream begins while blood is still in the pulmonary arterioles (14). The possibility that ether might begin to diffuse from the blood stream into the alveoli in the arterioles rather than in the capillaries has to be considered. If this occurs, the volume measured by the method under discussion would leave out an undetermined fraction of the blood in the pulmonary arterioles.

We have attempted to estimate the volume of gas that could diffuse through the arteriolar wall by substituting into the diffusion equation values for the total wall area, wall thickness, traversal time, ether concentration in blood and alveolar gas, and the coefficient of diffusion for ether in water.
For instance, for the arterioles, assuming a radius of $25 \mu$, a length of $0.4 \mathrm{~mm}$, the number of vessels as $5 \times 10^{8}$, an initial concentration of ether in the blood of $2 \times 10^{-3} \mathrm{ml}$ per ml blood, an initial concentration of ether in the alveoli of 0 , a wall thickness of $1 \mu$, and a time spent in the arterioles of 0.1 second (this value was obtained by estimating the volume in the arterioles and dividing it by an assumed cardiac output of $40 \mathrm{ml}$ per second), one finds that $0.13 \mathrm{ml}$ of liquid ether or $31 \mathrm{ml}$ of ether gas can pass through the arteriolar wall in the time available. Furthermore, the volume of tissue in the arteriolar wall, calculated to be $0.32 \mathrm{ml}$, is insufficient to absorb much ether. But once having penetrated the arteriolar wall, the ether is equilibrated with the gas and tissues in the vicinity of the arterioles; it will then penertate to the regions between alveoli by diffusion through the intervening gas and tissues. As this happens the concentration in the arteriole diminishes, until at diffusion equilibrium throughout the lung it will be a fraction of the initial concentration. Thus, the diffusion gradient would be correspondingly diminished. The equilibration process then becomes complete either when ether has penetrated the intervening gas and tissues by diffusion from the arterioles, or when it has been carried to the capillaries in solution in the blood stream by blood flow. Calculations show that either process may be completed within $0.1 \mathrm{sec}-$ ond of the time when ether arrives at the arteriolar vessels.

This approach, while theoretically sound, in practice yields uncertain answers because of the paucity of anatomic studies on the number, diameter, length, and wall thickness of the arterioles and the capillaries in the lung, and on the actual degree of proximity of the arterioles to alveolar gas.

\section{Applications}

1. Pulmonary circulatory dynamics. Our method measures the volume of blood in the vessels up to, but not including, those in which gas exchange takes place; thus, there should be no significant overlap with the pulmonary capillary blood volume measured by the $\mathrm{CO}$ method (6). It follows that the volume of blood in the pulmonary veins can be obtained by subtracting the vol- 
ume of blood in the arteries and in the capillaries from the total pulmonary blood volume. This method, although limited in accuracy, provides the investigator with means for studying, for the first time during life, problems such as the approximate site of blood accumulation in pulmonary congestive states, during changes in posture and in venous return, and the subdivisions of the pulmonary blood volume in pulmonary hypertension.

2. Regional ventilation, blood flow, and lung specific gravity. One interesting application of the method is in determining the specific gravity of the lung. The volume of ether gas that enters the alveoli can be calculated from an equation which can be solved for lung density (specific gravity) if the amount of gas evolved is determined from the plethysmograph record. Since the specific gravity of the lung is determined by the relative amounts of gas and fluid, changes in the specific gravity should indicate changes in the same direction in the amount of fluid in the lung. In complete atelectasis the specific gravity should be 1 . Injection of ether in alcohol into a lobar branch of the pulmonary artery would similarly yield information on the amount of fluid in the lobe supplied.

The relative volume of air going to each lung during inflation may be measured by injecting ether into the right and left branches of the pulmonary artery while the breath is held in full expiration and then in full inspiration (4 injections). The change in lung density would be greater in the lung receiving more air per unit weight. In addition, the rate of blood flow per unit alveolar volume may be calculated as follows: the rate of reabsorption of ether from the lung is

$$
\frac{d \mathrm{~V}_{\mathrm{e}}}{d t}=\mathrm{F}_{\mathrm{A}_{\mathrm{e}}} \cdot \alpha_{\mathrm{e}} \cdot \dot{\mathrm{Q}}_{\mathrm{c}}
$$

where $V_{e}$ is the volume of ether reabsorbed from the alveolar air, lung tissue, and pulmonary capillary blood; $\mathrm{FA}_{\mathrm{e}}$ is the fraction of ether in alveolar air ; and $\alpha_{e}$ is the partition coefficient of ether between blood and gas, and is equal to 15.5.

The change in volume of alveolar gas owing to reabsorption of ether from alveolar air is:

$$
\frac{d \mathrm{VA}}{d t}=\frac{\mathrm{VA}_{\mathrm{e}(\max )}}{26} \cdot \frac{d \mathrm{~V}_{\mathrm{e}}}{d t}
$$

where $\mathrm{VA}$ is alveolar volume, $\mathrm{VA}_{\mathbf{e}(\max )}$ is the vol- ume of ether gas evolved, and 26 is the volume of ether gas that would be formed by warming $0.1 \mathrm{ml}$ of liquid ether to $37^{\circ} \mathrm{C}$ (BTPS). The expression $\mathrm{VA}_{\mathbf{e}(\max )} / 26$ is used rather than $\mathrm{VA}_{\mathbf{e}}$ because the alveolar ether is only a fraction of the gas resulting from the vaporization of $0.1 \mathrm{ml}$ of liquid ether, and is in equilibrium with the ether dissolved in the lung tissues and the pulmonary capillary blood.

The fraction of alveolar ether, $F_{A_{e}}$, may be expressed as:

$$
\mathrm{FA}_{\mathrm{e}}=\frac{\mathrm{VA}_{\mathrm{e}}}{\mathrm{VA}_{\mathrm{A}}}
$$

where $\mathrm{VA}_{\mathrm{A}}$ is the alveolar volume in milliliters BTPS. Substituting Equations 2 and 3 into Equation 1 and solving for blood flow per unit alveolar volume, one obtains :

$$
\frac{\dot{\mathrm{Q}}_{\mathrm{c}}}{\mathrm{V}_{\mathrm{A}}}=\frac{26}{15.5 \times \mathrm{VA}_{\mathrm{A}_{(\mathrm{max})}}} \cdot \frac{d \mathrm{VA}_{\mathrm{A}_{\mathrm{e}}}}{\mathrm{VA}_{\mathrm{e}} \cdot d t}
$$

where $d \mathrm{VA}_{\mathrm{e}} / \mathrm{VA}_{\mathrm{e}} d t$ is the fractional change in gas volume per unit time, and which can be accounted for completely by the change in ether volume. For example, assume that $5 \mathrm{ml}$ (BTPS) of ether gas enters the alveoli after injection of $0.1 \mathrm{ml}$ of liquid ether, and is then reabsorbed at a rate of 10 per cent per second. The blood flow per unit alveolar volume would be:

$\frac{\dot{\mathrm{Q}}_{\mathrm{c}}}{\mathrm{VA}_{\mathrm{A}}}=\frac{26}{15.5 \times 5} \times 0.1=0.034 \mathrm{ml}$ per second per $\mathrm{ml} \mathrm{BTPS}$, or $34 \mathrm{ml}$ per second per L of gas.

Similarly, injections into the right and left pulmonary artery theoretically could provide information about the ventilation and the blood flow of each lung separately.

3. Pulmonary artery compliance. While two methods are now available for measuring the compliance $(\Delta \mathrm{V} / \Delta \mathrm{P})$ of the pulmonary arterial tree during life (15), the inability to measure its volume precluded an assessment of the distensibility $(\Delta \mathrm{V} / \Delta \mathrm{P}) / \mathrm{V}(16)$ of the pulmonary arterial tree. The ether method herein described, by providing a means for measuring the volume of blood in the pulmonary arteries, makes possible the determination not only of the slope but also of the intercept on the volume axis of the compliance curve, thus providing a measurement of the distensibility of 
the pulmonary arterial system. An example follows: The compliance of the pulmonary arteries can be calculated by the pulse profile method (15) from the equation, $C=\tau / R$, where $R$ is the pulmonary vascular resistance and $\tau$ is the time taken from the dicrotic notch to the point on the time axis at which the pulmonary artery pressure has fallen by 64 per cent of the difference between the pressure at the dicrotic notch and the left atrial (or in normal cases the pulmonary artery diastolic) pressure. In Dog 3 the pulmonary vascular resistance is calculated, assuming a mean pulmonary artery to left atrium pressure gradient of $10 \mathrm{~mm} \mathrm{Hg}$, from $\mathrm{R}=(10 \times 1.36 \times 60) / 1902$ $=0.43 \mathrm{~cm} \mathrm{H}_{2} \mathrm{O}$ per $\mathrm{ml}$ per second; $\tau$ was measured and found to be 0.28 second. $\mathrm{C}=0.28 / 0.43$ $=0.65 \mathrm{ml}$ per $\mathrm{cm} \mathrm{H}_{2} \mathrm{O}$.

The volumetric distensibility of the pulmonary artery equals $(0.65 / 35) \times 100=1.9$ per cent per $\mathrm{cm} \mathrm{H}_{2} \mathrm{O}$. Assuming a pulse pressure of $15 \mathrm{~mm}$ $\mathrm{Hg}$, the distension during systole equals $1.9 \times$ $1.36 \times 15=39$ per cent of its mean volume.

It must be pointed out that it would be possible to obtain a measurement of compliance using the ether method itself, by inducing changes in the pulmonary artery pressure and obtaining a series of pressure-volume points, provided that the stimulus used does not alter the tone of the pulmonary arteries.

4. Gas exchange kinetics. Since ether is an inert gas and therefore equilibrates very rapidly across the vascular wall in the lung (17), the time it takes to appear in the alveoli is virtually the time it spends in the blood stream prior to reaching the site of gas exchange. On the other hand, a gas that reacts chemically with the blood, such as $\mathrm{CO}_{2}$, might take a longer time to be liberated from its chemical combination, and should appear in the alveoli later than ether. The difference between the arrival time in the alveoli of ether and of $\mathrm{CO}_{2}$ should represent the time taken by the over-all dissociation and diffusion reaction of $\mathrm{CO}_{2}$ from the blood. The reaction of $\mathrm{CO}_{2}$ with the blood has been studied by the injection of lactic acid into the pulmonary artery of a dog enclosed within a body plethysmograph (18). In the present study and in similar studies (18) the injection of ether was used to fix the time of arrival of the injected substance at the site of gas exchange. These observations will be published in detail else- where, but they serve to demonstrate the application of this method of determining the pulmonary arterial circulation time in the study of the kinetics of respiratory gas exchange. This is the only preparation that permits such studies in living organisms.

\section{Precautions}

The method has not yet been tried in humans. Fatalities in dogs, when they occur, can usually be attributed to causes other than the injection of ether. It seems unlikely that the amounts of ether $(0.1 \mathrm{ml}$ per injection) or of alcohol $(0.4 \mathrm{ml}$ per injection) should give untoward reactions if the number of injections is kept reasonably small. In general it is advisable to observe the precautions used during ordinary cardiac catheterization and during the use of ether for measuring the circulation time in man (a procedure now subject to the criticism that the ether forms ether gas bubbles in the blood stream unless a suitable vehicle for the ether is used).

\section{SUMMARY}

A new method is described for measuring the circulation time between the pulmonary artery and the vessels of gas exchange. One-half $\mathrm{ml}$ of a solution containing $0.1 \mathrm{ml}$ of liquid ether dissolved in either $0.4 \mathrm{ml}$ of alcohol or $0.4 \mathrm{ml}$ of lipid emulsion (Lipomul) was injected through a cardiac catheter into the main pulmonary artery during a brief period of apnea. The arrival of the ether within the intrapulmonary vessels of gas exchange was detected by the rise in pressure within a body plethysmograph.

The pulmonary arterial ether circulation time was measured several times in each of 12 dogs. In 5 of these, indocyanine green dye curves were obtained from the femoral artery after injection of dye alternately into the pulmonary artery and left atrium. In this group the average weight was $18.5 \mathrm{~kg}$, cardiac output was $2,750 \mathrm{ml}$ per minute, pulmonary arterial ether circulation time was 1.1 seconds, pulmonary circulation time (pulmonary artery to left atrium) was 4.1 seconds, pulmonary arterial blood volume was $51 \mathrm{ml}$, pulmonary blood volume was $190 \mathrm{ml}$, volume of ether gas evolved was $5.5 \mathrm{ml}$, and lung density, calculated by using the partition coefficient of ether, was $0.23 \mathrm{~g}$ per $\mathrm{ml}$. 
In addition, this method will permit the measurement of the time of arrival of other injected substances, such as lactic acid, within the vessels of gas exchange in order to study the rate of dissociation of carbon dioxide from the blood.

\section{REFERENCES}

1. Stewart, G. N. The pulmonary circulation time, the quantity of blood in the lungs and the output of the heart. Amer. J. Physiol. 1921, 58, 20.

2. Hamilton, W. F., Moore, J. W., Kinsman, J. M., and Spurling, R. G. Studies on the circulation. IV. Further analysis of the injection method, and of changes in hemodynamics under physiological and pathological conditions. Amer. J. Physiol. 1932, 99, 534.

3. Meier, P., and Zierler, K. L. On the theory of the indicator-dilution method for measurement of blood flow and volume. J. appl. Physiol. 1954, 6, 731.

4. Dock, D. S., Kraus, W. L., McGuire, L. B., Hyland, J. W., Haynes, F. W., and Dexter, L. The pulmonary blood volume in man. J. clin. Invest. 1961, 40, 317.

5. Milnor, W. R., Jose, A. D., and McGaff, C. J. Pulmonary vascular volume, resistance, and compliance in man. Circulation 1960, 22, 130.

6. Roughton, F. J. W., and Forster, R. E. Relative importance of diffusion and chemical reaction rates in determining rate of exchange of gases in the human lung, with special reference to true diffusing capacity of pulmonary membrane and volume of blood in the lung capillaries. J. appl. Physiol. 1957, 11, 290.

7. Forster, R. E. Exchange of gases between alveolar air and pulmonary capillary blood: Pulmonary diffusing capacity. Physiol. Rev. 1957, 37, 391.
8. Roughton, F. J. W. Average time spent by blood in human lung capillary and its relation to the rates of $\mathrm{CO}$ uptake and elimination in man. Amer. J. Physiol. 1945, 143, 621.

9. Allison, P. R., and Linden, R. J. The bronchoscopic measurement of left auricular pressure. Circulation 1953, 7, 669.

10. Orcutt, F. S., and Seevers, M. H. The solubility coefficient of cyclopropane for water, oils and human blood. J. Pharmacol. exp. Ther. 1937, 59, 206.

11. Piiper, J. Dehnbarkeit des arteriellen und des venösen Teils des Gefässsystems der isolierten durchbluteten Hundelunge. Pflüg. Arch. ges. Physiol. 1959, 268, 545.

12. DuBois, A. B., and Ross, B. B. A new method for studying mechanics of breathing using cathode ray oscillograph. Proc. Soc. exp. Biol. (N. Y.) 1951, 78, 546.

13. Kjellberg, S. R., Mannheimer, E., Rudhe, U., and Jonsson, B. Diagnosis of Congenital Heart Disease. Chicago, Year Book Publishers, 1955, pp. 435, 493.

14. Staub, N. C. Gas exchange vessels in the cat lung. Fed. Proc. 1961, 20, 107.

15. Engelberg, J., and DuBois, A. B. Mechanics of pulmonary circulation in isolated rabbit lungs. Amer. J. Physiol. 1959, 196, 401.

16. Remington, J. W. Tissue Elasticity. Washington, D. C., American Physiological Society, 1957.

17. Kety, S. S. Theory and applications of exchange of inert gas at lungs and tissues. Pharmacol. Rev. 1951, 3, 1.

18. Soni, J., Feisal, K. A., and DuBois, A. B. Transcapillary blood gas reaction kinetics measured in living animals. Physiologist 1961, 4, 114. 